\title{
The influence of supplementary light on Dorper lambs fed intensively
}

\author{
P.J. Fourie ${ }^{\#}$ P.J.A. Vos and S.S. Abiola \\ Department of Agriculture, Central University of Technology, Free State, Private Bag X20539, \\ Bloemfontein 9300, South Africa
}

\begin{abstract}
The objective of this trial was to quantify the differences in average daily gain (ADG), backfat thickness (BFT), eye muscle area (EMA), fat thickness (FT) on different body parts, the feed conversion ratio (FCR), body measurements and the weight of internal organs of Dorper lambs exposed to supplemented light. For this study 120 Dorper lambs (115 \pm 10 days old), weighing $29.8 \pm 5.01 \mathrm{~kg}$, were used. The lambs were randomly divided into three homogeneous groups (20 castrated and 20 intact males/group). Two groups were then exposed to either $16 \mathrm{~h}$ or $24 \mathrm{~h}$ of supplemented light at $145 \mathrm{lux}$, and a control the normal photoperiod. The animals were fed ad libitum with pellets containing $9.5 \mathrm{MJ}$ ME/kg DM and $120 \mathrm{~g} \mathrm{CP} / \mathrm{kg}$ in open pens. The animals were weighed every seven days while ultrasound scanning of the EMA and BFT was done at the beginning and the end of the $35 \mathrm{~d}$ trial. The ADG, FCR and feed intake (FI) were calculated at the end of the trial. Linear body measurements including shoulder height, body length and heart girth were taken at days 1 and 35. All the animals were slaughtered at the end of the trial. The carcasses were weighed, graded and the FT was measured with a caliper. It was concluded that there are no differences between treatments in terms of body measurements, ultrasound scanning, ADG and FCR.
\end{abstract}

Keywords: Light supplementation, photoperiod, Dorper lambs, intensive feeding

\#Corresponding author. E-mail address: pfourie@cut.ac.za

\section{Introduction}

There are indications that the demand for mutton and lamb will soon exceed supply should the current mainly extensive, production systems be retained (Louw \& Read, 1991). The question arises whether the feedlotting of sheep should be expanded. Intensive feeding involves the withdrawal of animals from veld (natural pasture) and providing them with a higher level of nutrition in a feedlot, and could include the strategic use of cultivated pastures. The intensive feeding and finishing of sheep is a highly specialized business which requires a high level of management ability to ensure success (Louw \& Read, 1991). A sound knowledge of nutrition, diseases and market prices is essential for such an undertaking to be successful. In any intensive production system factors such as management, housing and feeding are of the utmost importance (Louw \& Read, 1991; Bertram \& Phillips, 2004).

A factor that may in the near future have a huge impact on the performance of animals under feedlot conditions is light manipulation (Fourie et al., 2006). Photoperiod management is used by many milk producers to increase profits. Photoperiod is defined as the duration of light an animal is exposed to in a 24-h period (Dahl, 2001; Small et al., 2003). Animals use photoperiod to track the length of the day. A long-day photoperiod is considered exposure to 16 - $18 \mathrm{~h}$ of light associated with a 6 - $8 \mathrm{~h}$ period of darkness. In contrast, a short-day photoperiod is usually $8 \mathrm{~h}$ of light and $16 \mathrm{~h}$ of darkness (Dahl, 2001). Small et al. (2003) and Kennedy et al. (2004) conducted studies on the effect of supplemented light on beef heifers and significant improvements were found in terms of growth and carcass composition. Long days have consistently been shown to improve milk yield during established lactations (Dahl et al., 2000). In addition, photoperiod management can be used to improve heifer growth and maximize accretion of lean tissue, including mammary parenchyma (Dahl \& Peticlerc, 2003).

The Dorper is generally recognized as one of the most popular mutton breeds in South Africa. It is well adapted to a variety of veld types and climates, and is farmed over a wide geographical range in this country (Nel, 1993). The Dorper is a medium maturing sheep that will reach optimum slaughter weight at 34 - 38 kg (Maree \& Casey, 1993).

The questions that arise are whether light manipulation will affect the feedlot performance of Dorper lambs. The objective of this study was therefore to evaluate the effect of different photoperiods on the ADG, 
average feed intake (FI), back fat thickness (BFT), eye muscle area (EMA), dressing\% and feed conversion ratio (FCR), and the weight of the internal organs as well as to determine whether light supplementation has any effect on body dimensions of animals exposed to different daylenghts.

\section{Materials and Methods}

One hundred and twenty Dorper lambs, $115 \pm 10$ days of age, weighing $29.8 \pm 0.82 \mathrm{~kg}$, were used. The animals were divided into three homogeneous groups of 40 animals/group blocked according to weight and age. In each group 20 were intact males and 20 castrated males. The lambs were born and raised on veld. During the trial period, the animals were housed in open pens and weighed every seven days. After adaptation the lambs were fed a diet containing $120 \mathrm{~g} \mathrm{CP} / \mathrm{kg}$ and $9.5 \mathrm{MJ} \mathrm{ME} / \mathrm{kg} / \mathrm{DM}$ ad libitum for 35 days. The artificial source of light comprised high pressure sodium lights giving a light intensity of 145 lux measured at eye level, as measured with a digital illumination meter (INS DX 200). At the end of the trial all the lambs were slaughtered. The following data were recorded: Initial and final weight (FW), linear body measurements, subcutaneous fat depth between the $12^{\text {th }}$ and $13^{\text {th }}$ rib (BFT), longissimus dorsi (EMA) (taken on days 1 and 35), measured with a PIE Medical Falco 100 ultrasound scanner as well as average feed intake per group (FI), average daily gain (ADG) and feed conversion ratio (FCR). The following measurements were taken after the slaughtering of all animals: warm carcass weight (WCW), weight of the internal organs (heart, liver, lungs and abdominal fat), rump fat, rib fat, grading and dressing \%. Linear body measurements including shoulder height, body length and heart girth were taken at day 1 and day 35, respectively.

The following treatments were applied:

Group 1: Lights were manually switched off at dawn, and switched on half an hour before sunset, so that the animals did not experience natural sunset before the beginning of supplemented light. This group was subjected to $24 \mathrm{~h}$ light. No cloud cover ocurred during the trial.

Group 2: The lights were switched on by means of an automatic timer and the duration was adjusted twice a week as the daylight decreased in order to expose the lambs to $16 \mathrm{~h}$ light and $8 \mathrm{~h}$ darkness/day.

Group 3: This group served as the control group and only received natural photoperiods (NP). All the pens were far away from each other, preventing artificial light to reflect on this group and have an influence on the natural light conditions.

Data was statistically analysed using a one-way ANOVA in Proc GLM to determine the effect of supplemented light on the different parameters.

\section{Results and Discussions}

For ADG, the 16L:8D and the 24L:0D group performed slightly better than the NP group $(0.22,0.23$ and $0.23 \mathrm{~kg} /$ animal/day) although these differences are not significant $(\mathrm{P}>0.05)$ (Table 1$)$. These results concur with those of Hackett \& Hillers (1979) who also recorded no differences $(\mathrm{P}>0.05)$ between the treatments for daily gain or efficiency of feed utilization. Artificial lighting in the lamb feedlot neither increased growth rate nor improved feed efficiency of feeder lambs. Hullet et al. (1968) concluded that light treatment had little or no effect on bodyweight changes. However, Fourie et al. (2006) reported that the ADG of young beef bulls subjected to $24 \mathrm{~h}$ light were higher $(\mathrm{P}<0.05)$ than that of bulls subjected to $16 \mathrm{~L}: 8 \mathrm{D}$ and normal conditions. Body weights of the lambs exposed to NP, 16L: 8D and 24L: 0D averaged at $29.8 \pm$ $0.81,30.0 \pm 0.83$ and $29.5 \pm 0.81 \mathrm{~kg}$ at the start of the trial and increased to $37.4 \pm 0.96,38.0 \pm 0.98$ and 37.5 $\pm 0.96 \mathrm{~kg}$, respectively at the end of the trial. The total weight gained for the NP group was $7.59 \mathrm{~kg}, 8.0 \mathrm{~kg}$ for the 16L: $8 \mathrm{D}$ group and $8.08 \mathrm{~kg}$ for the $24 \mathrm{~L}$ : $0 \mathrm{D}$ group. There was a correlation of 0.82 between WCW and body length (BL). The correlation between WCW and shoulder height (SH) was 0.62 and 0.91 between heart girth (HG) and WCW. This indicates that HG had a bigger influence on the WCW than the BL and $\mathrm{SH}$.

The FCR of the different groups were 7.18 (NP), 7.15 (16L:8D) and 6.86 (24L:0D) respectively. The dressing percentage of the lambs in NP group was $45.2 \%, 45.7 \%$ for the $16 \mathrm{~L}: 8 \mathrm{D}$ group and $45.8 \%$ for the 24L:0D group.

The fat measurements of carcasses from the different treatments did not differ significantly $(\mathrm{P}<0.05)$. There were no differences $(\mathrm{P}<0.05)$ in the weight of the heart, liver, lungs and abdominal fat between the groups. Schanbacher \& Crouse (1980) reported that although the carcass traits of backfat thickness, kidney and pelvic fat, quality grade and yield grade were significantly affected by gender, these traits were not 
influenced by photoperiod. Corrected EMA differed $(\mathrm{P}<0.05)$ between the 16L:8:D light and 24:L:0D treatment groups, with the latter having the largest EMA.

Table 1 The effect of supplemented light on body weight, final body weight, warm carcass weight and average daily gain (mean \pm s.e.) of Dorper lambs fed intensively

\begin{tabular}{lccc}
\hline Parameter & $\begin{array}{c}\mathrm{NP} \\
(\mathrm{n}=40)\end{array}$ & $\begin{array}{c}\text { 16L: 8D } \\
(\mathrm{n}=38)\end{array}$ & $\begin{array}{c}\text { 24L: 0D } \\
(\mathrm{n}=40)\end{array}$ \\
\hline Body weight start $(\mathrm{kg})$ & $29.8 \pm 0.81$ & $30.0 \pm 0.83$ & $29.5 \pm 0.81$ \\
Final body weight $(\mathrm{kg})$ & $37.4 \pm 0.96$ & $38.0 \pm 0.98$ & $37.5 \pm 0.96$ \\
Warm carcass weight $(\mathrm{kg})$ & $17.6 \pm 0.48$ & $17.9 \pm 0.50$ & $17.8 \pm 0.48$ \\
Average daily gain $(\mathrm{kg})$ & $0.22 \pm 0.01$ & $0.23 \pm 0.01$ & $0.23 \pm 0.01$ \\
\hline
\end{tabular}

NP - natural photoperiods; 16L:8:D- 16 h light; 24:L:0D- 24 h of light.

Table 2 The effect of supplemented light on grading, carcass conformation, fat thickness on rib, heart weight, liver weight, weight of lungs, abdominal fat, corrected eye muscle area at start, rump fat and corrected eye muscle area (mean \pm s.e.) of Dorper lambs fed intensively

\begin{tabular}{lccc}
\hline Parameter & $\begin{array}{c}\mathrm{NP} \\
(\mathrm{n}=40)\end{array}$ & $\begin{array}{c}16 \mathrm{~L}: 8 \mathrm{D} \\
(\mathrm{n}=38)\end{array}$ & $\begin{array}{c}24 \mathrm{~L}: 0 \mathrm{D} \\
(\mathrm{n}=40)\end{array}$ \\
\hline Grading $(0-6)$ & $1.82 \pm 6.36$ & $1.72 \pm 6.53$ & $1.84 \pm 6.36$ \\
$\begin{array}{l}\text { Carcass conformation } \\
(1-5)\end{array}$ & $4.02^{\mathrm{a}} \pm 0.12$ & $4.43^{\mathrm{b}} \pm 0.13$ & $4.17^{\mathrm{b}} \pm 0.12$ \\
Fat thickness rib (mm) & $1.32 \pm 8.93$ & $1.49 \pm 9.16$ & $1.57 \pm 8.93$ \\
$\begin{array}{l}\text { Heart weight (g) } \\
\text { Liver weight (g) }\end{array}$ & $160.7 \pm 3.16$ & $155.8 \pm 3.24$ & $155.3 \pm 3.16$ \\
$\begin{array}{l}\text { Weight of lungs (g) } \\
\text { Abdominal fat (g) }\end{array}$ & $712.3 \pm 24.5$ & $725.4 \pm 25.14$ & $698.5 \pm 24.5$ \\
$\begin{array}{l}\text { Corrected eye muscle } \\
\text { area (start) }\left(\mathrm{cm}^{2}\right)\end{array}$ & $10.01 \pm 0.20$ & $739.2 \pm 21.45$ & $771.5 \pm 20.91$ \\
Rump fat (mm) & $4.67 \pm 0.14$ & $267.1 \pm 21.65$ & $264.8 \pm 21.1$ \\
$\begin{array}{l}\text { Corrected eye muscle } \\
\text { area }\left(\mathrm{cm}^{2}\right)\end{array}$ & $15.67^{\mathrm{a}} \pm 0.31$ & $10.38 \pm 0.21$ & $9.97 \pm 0.20$ \\
\hline
\end{tabular}

Means with different superscripts within the same row differ significantly: $\mathrm{P}<0.05$.

NP - natural photoperiods; 16L:8:D- 16 h light; 24:L:0D- 24 h of light.

Body length, shoulder height and heart girth did not differ significantly between the treatment groups. Heart girth (HG) is generally accepted as the most reliable indicator (Benyi, 1997) of growth (body weight). The following positive correlations were recorded: The highest correlation of $0.92(\mathrm{P}<0.0001)$ was found between HG and FW. This correlation is even higher than the correlation between body length (BL) and 
body weight, which had a correlation of 0.81 ( $\mathrm{P}<0.0001)$. Fourie et al. (2002) reported a correlation of 0.80 $(\mathrm{P}<0.001)$ between HG and BW and a correlation of $0.76(\mathrm{P}<0.001)$ between BL and BW in Dorper rams.

\section{Conclusions}

It is concluded that supplemented light has no significant effect on growth, feed efficiency, fat deposition, dressing\%, body dimensions or the weight of the internal organs of Dorper lambs.

\section{References}

Benyi, K., 1997. Estimation of live weight from chest girth in pure and crossbred West African goats. Trop. Anim. Health Prod. 29, 124-128.

Bertram, J. \& Phillips, A., 2004. Basic Guidelines for a Feetlot Operation. Anim. Prod. Alice, Springs. 1-6.

Dahl, G.E., 2001. Photoperiod control improves production of dairy cows. Feedstuffs: a weekly newspaper for the feed manufacturer, feed jobber, feed broke and feed dealer. 73, 10-19.

Dahl, G.E. \& Peticlerc, D., 2003. Management of photoperiod in dairy herd for improved production and heath. J. Anim. Sci. 81, 11-17.

Dahl, G.E., Buchanan, B.A. \& Tucker, H.A., 2000. Photoperiodic effects on dairy cattle: A review. J. Dairy Sci. 83, 885-893.

Fourie, P.J., Neser, F.W.C., Olivier, J.J. \& Van der Westhuizen, C., 2002. Relationship between production performance and body measurements of Dorper rams. S. Afr. J. Anim. Sci. 32, 256-262.

Fourie, P.J., Maasz, D.J. \& Umesiobi, D.O., 2006. The effect of supplemented light on certain production parameters of young beef bulls fed intensively. S. Afr. J. Anim. Sci. 36, 59-62.

Hackett, M.R. \& Hillers, J.K., 1979. Effects of artificial lightning on feeder lamb performance. J. Anim. Sci. 49, 1-4.

Hulet, C.V., Price, D.A. \& Foote, W.C., 1968. Effects of variation in light, month of year and nutrient intake on reproductive phenomena in ewes during the breeding season. J. Anim. Sci. 27, 684-690.

Kennedy, A.D., Bergen, R.D., Lawson, T.J., Small, J.A. \& Veira, D.M., 2004. Effects of evening feeding and extended photoperiod on growth, feed efficiency, live animal carcass traits and plasma proclactin of beef heifers housed outdoors during two Manitoba winters. Can. J. Anim. Sci. 3, 491-500.

Louw, C.J. \& Read, M., 1991. Intensive feeding and finishing of lambs and culls. Natal Sheep 5.5 Department of Agricultural Development . Natal Region Pietermaritzburg. pp. 1-4.

Maree, C. \& Casey, N.H., 1993. Livestock Production Systems: Principles and Practice. Agri-Development Foundation, Brooklyn, Pretoria, South Africa.

Nel, J.A., 1993. History of the Dorper (in Afrikaans). Dorper Sheep Breeder's Society of South Africa, P.O. Box 26, Middelburg, C.P. 5900, South Africa.

Schanbacher, B.D. \& Crouse, J.D., 1980. Growth and performance of growing-finishing lambs exposed to long or short photoperiods. J. Anim. Sci. 51, 943-948.

Small, J.A., Glover, N.D., Kennedy, A.D., McCaughey, W.P. \& Ward, D.R., 2003. Photoperiod effects on the development of beef heifers. Can. J. Anim. Sci. 83, 721-730. 